\title{
Interest in Low-Threshold Employment among People who Inject Illicit Drugs: Implications for Street Disorder
}

\author{
Kora DeBeck ${ }^{1}$, Evan Wood ${ }^{1,2}$, Jiezhi Qi ${ }^{1}$, Eric Fu ${ }^{1}$, Doug McArthur ${ }^{3}$, Julio Montaner ${ }^{1,2}$, and \\ Thomas Kerr ${ }^{1,2}$ \\ ${ }^{1}$ British Columbia Centre for Excellence in HIV/AIDS \\ 2 Division of AIDS, Department of Medicine, University of British Columbia \\ ${ }^{3}$ School of Public Policy, Simon Fraser University
}

Abstract

Background-Income generation opportunities available to people who use illicit drugs have been associated with street disorder. Among a cohort of injection drug users (IDU) we sought to examine street-based income generation practices and willingness to forgo these sources of income if other low-threshold work opportunities were made available.

Methods-Data were derived from a prospective community recruited cohort of IDU. We assessed the prevalence of engaging in disorderly street-based income generation activities, including sex work, drug dealing, panhandling, and recycling/salvaging/vending. Using multivariate logistic regressions based on Akaike information criterion and the best subset selection procedure, we identified factors associated with disorderly income generation activities, and assessed willingness to forgo these sources of income during the period of November 2008 to July 2009.

Results-Among our sample of 874 IDU, 418 (48\%) reported engaging in a disorderly income generation activity in the previous six months. In multivariate analyses, engaging in disorderly income generation activities was independently associated with high intensity stimulant use, as well as binge drug use, having encounters with police, being a victim of violence, sharing used syringes, and injecting in public areas. Among those engaged in disorderly income generation, 198 (47\%) reported a willingness to forgo these income sources if given opportunities for lowthreshold employment, with sex workers being most willing to engage in alternative employment.

Conclusion-Engagement in disorderly street-based income generation activities was associated with high intensity stimulant drug use and various markers of risk. We found that a high proportion of illicit drug users were willing to cease engagement in these activities if they had options for causal low-threshold employment. These findings indicate that there is a high demand

(C) 2011 Elsevier B.V. All rights reserved.

Send correspondence to: Thomas Kerr, PhD, BC Centre for Excellence in HIV/AIDS, 608-1081 Burrard Street, Vancouver, B.C., CANADA V6Z 1Y6, Tel: (604) 806-9116, uhri-tk@cfenet.ubc.ca.

Competing Interests:

Dr. Julio Montaner has received grants from, served as an ad hoc advisor to, or spoke at various events sponsored by; Abbott, Argos Therapeutics, Bioject Inc, Boehringer Ingelheim, BMS, Gilead Sciences, GlaxoSmithKline, Hoffmann-La Roche, Janssen-Ortho, Merck Frosst, Pfizer, Schering, Serono Inc, TheraTechnologies, Tibotec, Trimeris.

Authors declare no other competing interests.

Publisher's Disclaimer: This is a PDF file of an unedited manuscript that has been accepted for publication. As a service to our customers we are providing this early version of the manuscript. The manuscript will undergo copyediting, typesetting, and review of the resulting proof before it is published in its final citable form. Please note that during the production process errors may be discovered which could affect the content, and all legal disclaimers that apply to the journal pertain. 
for low-threshold employment that may offer important opportunities to reduce drug-related street disorder and associated harms.

\section{Keywords}

injection drug use; income generation; low-threshold employment; sex work; drug dealing; panhandling

\section{INTRODUCTION}

There are many established links between chronic illicit drug use and engagement in illegal income generation activities (Ball, Shaffer, \& Nurco, 1983; Bretteville-Jensen \& Sutton, 1996; Deschenes \& Anglin, 1991; Fischier et al., 2001; Hammersley et al., 1989; Nurco, Cisin, \& Ball, 1985; Silverman \& Spruill, 1977). People who use illicit drugs and are struggling with addiction are often unable to acquire and sustain formal employment, and yet the high costs associated with obtaining illicit drugs requires individuals to find means of generating income (Bretteville-Jensen \& Sutton, 1996; Cross et al., 2001; McCoy, Comerford, \& Metsch, 2007; Platt, 1995; Richardson et al., 2008; Richardson et al., 2010). Given these constraints, the income generation opportunities available to illicit drug users frequently involve illegal activity and are often associated with street disorder (BrettevilleJensen \& Sutton, 1996; DeBeck et al., 2007). For example, common income generation strategies include street-based sex work, drug dealing, panhandling and recycling/salvaging/ vending which often take place on public streets and are generally considered to be undesirable activities from a community perspective (Bose \& Hwang, 2002; Collins \& Blomley, 2003; DeBeck et al., 2007; Kerr et al., 2008; Shannon et al., 2007a). In Vancouver, Canada these types of disorderly income generation activities are a well described feature of the city's drug use epicentre known as the Downtown Eastside [DTES] (DeBeck et al., 2007; Kerr et al., 2008; Shannon et al., 2007a).

To date, policy responses to address problems associated with illicit drug use, including street disorder resulting from the income generation activities of illicit drug users, typically rely on law enforcement to deter and manage undesirable practices and behaviours (Boyum \& Reuter, 2005; DeBeck et al., 2006;L. Maher, 2000; National Research Council, 2002). However, it has been documented that in many instances law enforcement initiatives seeking to reduce street disorder result in displacing disorderly activities to surrounding neighbourhoods (Aitken at al., 2002; Maher \& Dixon, 1999; Wood et al., 2004). This has been shown to negatively impact communities and separate vulnerable drug users from familiar health and social services (Aitken at al., 2002; Cooper, Wypij, \& Krieger, 2005; Maher \& Dixon, 1999; Wood et al., 2004). Given these harms and the limited effectiveness of law enforcement in this area, alternative approaches to managing street disorder are required.

A growing body of health research suggests that interventions, such as law enforcement, that primarily target the behaviour of individuals may be limited in their effectiveness and inadvertently produce harm because they fail to recognize and address the role that social and structural factors play in shaping behaviour (Blankenship et al., 2006; Galea, Ahern, \& Vlahov, 2003; Rhodes, 2002; Sumartojo, 2000). Rhodes' Risk Environment Framework has been used to illustrate the importance of considering factors exogenous to the individual when examining drug-related harm (Rhodes, 2002; Rhodes et al., 2005; Rhodes, 2009). According to this framework, social, structural, and environmental level factors create a context that shapes individual behaviour and decision-making (Rhodes, 2002; Rhodes et al., 2003). From this perspective, risk is not only a product of individual behaviour, but is shaped and structured by laws, policies, and social relations that surround individuals. 
Targets for policy intervention, therefore, involve altering social and structural environments (Blankenship, Bray, \& Merson, 2000; Des Jarlais, 2000; Heimer et al., 2002). The problem of disorderly income generation is therefore not solely a matter of individuals choosing to engage in undesirable practices; rather, disorderly income generation is shaped by environmental, social and structural conditions. In turn, one potential approach to reducing street disorder is to change the structural environment surrounding individuals who use drugs by creating sanctioned low-threshold employment opportunities.

The concept of 'low-threshold' is to create programs that are easily accessible for active drug users and a key component of low-threshold programs is that they do not require abstinence from drug use. A recent longitudinal analysis among Vancouver based IDU revealed low levels of regular employment among study participants and also demonstrated that high intensity drug use was negatively associated with regular employment, highlighting the need for alternative employment strategies for this population (Richardson et al., 2010). Initial research suggests that low-threshold programs can engage streetinvolved drug users and reduce their participation in some types of disorderly income generation activities. An evaluation of a jewellery making economic empowerment program for women who use illicit drugs demonstrated that the program was associated with reductions in sex work involvement (Sherman et al., 2000).

In Vancouver, Canada there are a small number of existing low-threshold employment opportunities available to individuals who actively use illicit drugs. For example, in the DTES of Vancouver a community café and catering social enterprise company provides an estimated nine low-threshold employment positions (Lougheed-Green, 2004; Potluck catering), an organization that processes recyclable containers provides roughly 33 lowthreshold positions (Dale \& Newman, 2008; Lyotier, 2010), a local drug users group provides a small number of stipends for volunteer work undertaken by their members (Hayashi et al., 2010; Lloyd-Smith et al., 2010; VANDU, 2010) and a photo calendar project initiated by a social justice organization offers a program for residents of the DTES to become vendors and sell calendars and books (Grainger, November 30, 2008; Hope in Shadows, 2010; Moore \& Pell, 2010). Despite the existence of these opportunities, the number of low-threshold employment positions is limited and there is little information available to determine whether there is a significant demand for this type of work among individuals who currently engage in disorderly income generation activities.

Therefore, we sought to characterize the prevalence and correlates of engaging in disorderly income generation activities among a community recruited cohort of injection drug users (IDU) in Vancouver. We then sought to identify whether there was a demand for lowthreshold employment among those who were engaged in disorderly income generation to identify if this might be a suitable structural intervention to reduce one component of street disorder.

\section{METHODS}

Data for this study was obtained from the Vancouver Injection Drug Users Study (VIDUS), which is an open prospective cohort that began enrolling IDU through street outreach and self-referral in May 1996. This study has been described in detail previously (Kerr et al., 2007; Wood et al., 2002). In brief, to be eligible participants at recruitment must reside in the Greater Vancouver Regional District, have injected illicit drugs in the previous month, and provide written informed consent. At enrolment and on bi-annual basis participants complete an interviewer-administered questionnaire and provide a blood sample for serologic testing. At each study visit participants are provided with a stipend (\$20 CDN) for their time. The study has received ethics approval from St. Paul's Hospital/University of 
British Columbia's Research Ethics Board. The present analyses are restricted to those participants seen for study follow-up during the period of November 2008 to July 2009 as the measure for our outcome of interest was available only for this period. If individuals were seen for multiple study follow-up visits during this study period, only data from their first visit was used.

All participants seen during our study period were asked to identify all their income sources (over the last six months) and to estimate the average number of hours per week they spent engaged in each income generation activity over the last 30 days. Categories of income sources included recycling (includes salvaging recyclable materials and unsanctioned street vending), panhandling, squeegeeing, sex trade work and drug dealing. Other categories of income sources included welfare (including disability, pensions and other forms of government transfers), family and friends, regular job, temporary work (including under the table employment) and criminal activity (category encompasses a range of criminal activities including theft, break and entry, robbery and fraud).

To help determine whether low-threshold employment might have a positive effect on reducing street disorder, we began by evaluating factors associated with engaging in disorderly income generation. In this initial analysis the outcome of interest was engaging in 'disorderly income generation activities' defined as reporting any of the following income sources: recycling, squeegeeing, panhandling, selling drugs and exchanging sex for money. Although we were unable to confirm that all reported drug dealing and sex work activities occurred in public settings, a previous study among VIDUS participants found that both activities are independently associated with spending time in Vancouver's open drug scene suggesting that these activities are largely street-based (DeBeck, 2011). Reports in the 'criminal activity' category were not included in the 'disorderly income generation activities' category because the focus of our analysis was on street-disorder and the links between general criminal activities and street-disorder were unclear.

To characterize factors associated with engagement in disorderly income generation activities, we a priori selected a range of socio-demographic and behavioural variables based on previous literature on street disorder and income generation (DeBeck et al., 2011; DeBeck et al., 2007). We hypothesized that these variables would provide a profile of individuals engaged in disorderly income generation that could inform and direct policy interventions in this area. Variables included: age (per year older); daily expenditure on drugs (per additional \$10); gender (female vs. male); Aboriginal ancestry (yes vs. no); unstable housing, defined as currently living in a single occupancy room in a hotel, a treatment or recovery house, jail, shelter or hostel, or having no fixed address for the last six months (yes vs. no); high school education, defined as completing high school or obtaining equivalent diploma (yes vs. no); having regular employment, defined as having a regular or temporary job (yes vs. no); daily cocaine injection (yes vs. no); daily heroin injection (yes vs. no); daily crack cocaine smoking (yes vs. no); non-fatal overdose (yes vs. no), binge drug use, defined as a period of using drugs more often than usual (yes vs. no); encounters with police in the last month, defined as being questioned, searched or stopped by police (yes vs. no); being a victim of violence (yes vs. no); syringe sharing, defined as borrowing or lending syringes already used by someone else to inject drugs (yes vs. no); using injection drugs in public locations, such as city streets, parks and alleys (yes vs. no); engaging in any unprotected sex (yes vs. no); being recently incarcerated (yes vs. no); and current enrolment in methadone treatment (yes vs. no). Unless otherwise stated, all drug use and behavioural variables refer to the previous six month period.

In our primary analysis, we sought to assess whether a structural intervention in the form of low-threshold employment might have an impact on street disorder. To do this we measured 
demand for low-threshold employment and identified predictors of willingness to cease engagement in disorderly income generation activities if low-threshold employment was available. Our measures were based on the questions: If you were offered casual work that did not interfere with your welfare, would you take it? and If yes, are there any income sources in the last 30 days that you would eliminate? Participants were then asked to indicate which sources of income they would forgo. Variables of interest for this analysis included all variables from the primary analysis, in addition to engagement in specific disorderly income generation activities, including recycling, panhandling, squeegeeing, drug dealing and sex work. As in the initial analysis, unless otherwise stated, all drug use and behavioural variables refer to the previous six month period.

For both our analyses, we used logistic regression to determine factors associated with our outcomes of interest. In univariate analysis categorical explanatory variables were analyzed using Pearson's chi-square test and continuous variables were analyzed using the MannWhitney test. Fisher's exact test was used when one or more of the cell counts was less than or equal to five. To evaluate factors independently associated with our outcomes of interest, we used Akaike information criterion (AIC) with the best subset selection procedure. This provided a computationally efficient method to screen all possible combinations of candidate variables and identify the model with the best overall fit as indicated by the lowest AIC value (Shtatland et al., 2002). All statistical analyses were performed using SAS software version 9.1 (SAS, Cary, NC). All p-values are two sided.

\section{RESULTS}

During the study period a total of 874 participants completed follow-up visits, including 310 (35\%) women and $312(36 \%)$ persons who identified as being of Aboriginal ancestry. The median age of participants was 45 years (interquartile range $[\mathrm{IQR}]=39-51$ ). Among our sample of 874 IDU surveyed between November 2008 and July 2009, a total of 418 (48\%) reported engaging in disorderly income generation activities. The median number of disorderly activities that participants engaged in was $1(\mathrm{IQR}=1-1)$. As displayed in Table 1 , drug dealing $(\mathrm{n}=220,25 \%)$ and recycling $(\mathrm{n}=165,19 \%)$ were the most common types of disorderly income generation activity, and the median number of hours spent engaged in disorderly income generation activities each week was highest for drug dealing (20 hrs per week, IQR $=6-40$ ). The characteristics of the study sample stratified by engagement in disorderly income generation activities are presented in Table 2 .

Among individuals who reported engaging in disorderly income generation activities, 198 $(47 \%)$ indicated they would cease engaging in this activity if they had access to lowthreshold employment. As shown in Table 1, among those who reported income from sex trade work, $51(63 \%)$ indicated they would no longer engage in sex trade work if they had access to low-threshold employment. Further, 97 (44\%) respondents who reported income from drug dealing, 21 (37\%) respondents who reported engaging in panhandling and 48 (29\%) respondents who engaged in recycling reported that they would refrain from engaging in those disorderly income generation activities if they had access to causal employment opportunities.

The univariate and multivariate findings for our initial exploratory analyses of behavioral and socio-demographic variables associated with engaging in disorderly income generation activities are also presented in Table 2. Factors that remained independently associated with disorderly income generation activities included: regular employment (adjusted odds ratio $[\mathrm{AOR}]=0.47,95 \% \mathrm{CI}: 0.32-0.69)$; daily cocaine injection $(\mathrm{AOR}=2.11,95 \% \mathrm{CI}: 1.13-$ 3.96 ); daily crack cocaine smoking ( $\mathrm{AOR}=3.29,95 \% \mathrm{CI}$ : $2.32-4.66$ ); binge drug use (AOR $=1.57,95 \% \mathrm{CI}: 1.14-2.16)$; encounters with police $(\mathrm{AOR}=2.49,95 \% \mathrm{CI}: 1.65-3.75)$; being 
a victim of violence (AOR $=1.69,95 \% \mathrm{CI}$ : $1.07-2.68)$; syringe sharing $(\mathrm{AOR}=4.42$, 95\%CI: $1.43-13.68)$; and public injecting ( $\mathrm{AOR}=2.27,95 \% \mathrm{CI}: 1.51-3.39)$.

For our primary analysis, the univariate and multivariate results of factors associated with willingness to cease engaging in disorderly income generation activities are presented in Table 3. Factors that remained independently associated with willingness to cease engaging in disorderly income generation included: sex work (AOR $=2.32,95 \%$ CI: $1.35-3.96$ ); drug dealing (AOR $=1.91,95 \% \mathrm{CI}: 1.22-2.99)$; binge drug use (AOR $=1.55,95 \% \mathrm{CI}: 1.02-$ 2.36); incarceration ( $\mathrm{AOR}=2.03,95 \% \mathrm{CI}$ : 1.11-3.73); and current enrolment in methadone treatment $(\mathrm{AOR}=1.68,95 \% \mathrm{CI}: 1.11-2.56)$.

\section{DISCUSSION}

Among our sample of 874 IDU, we found that $48 \%$ reported engaging in a disorderly income generation activity in the last six months. The most common activities reported were drug dealing and recycling (which included salvaging and unsanctioned street vending). In a multivariate analysis people who reported engaging in disorderly income generation activities were more likely to smoke crack cocaine on a daily basis and inject cocaine on a daily basis. This population was also more likely to engage in binge drug use, have encounters with police, be a victim of violence, share used syringes and inject drugs in public areas. Conversely, individuals with regular employment were significantly less likely to report engaging in disorderly income generation activities. We also found that among individuals who engaged in disorderly income generation activities, $47 \%$ reported that they would be willing to stop engaging in these disorderly activities if they were offered other opportunities for low-threshold employment. Individuals engaged in sex work, drug dealing, binge drug use, who were recently incarcerated or currently enrolled in methadone therapy, were most interested in ceasing their engagement in disorderly income generation activities.

These findings support the conclusions of previous studies indicating that disorderly income generation activities are common among illicit drug users (Bretteville-Jensen \& Sutton, 1996; Cross et al., 2001; Deschenes \& Anglin, 1991; Nurco et al., 1985). The significant associations between engaging in disorderly income generation activities and daily crack cocaine smoking and daily cocaine injecting are consistent with a growing number of studies linking frequent cocaine use with a greater likelihood of engaging in risky behaviours (Booth, Kwiatkowski, \& Chitwood, 2000; Buchanan et al., 2006; Edlin et al., 1994) and illegal activities (Cross et al., 2001; DeBeck et al., 2007). These associations suggest that the compulsive drug acquisition behaviours associated with cocaine addiction may perpetuate the need to generate income through prohibited means. In particularly the relatively short half-life of cocaine compared with opioids or methamphetamine may contribute to an increased frequency of drug use and pressure to purchase larger quantities of drugs (Jeffcoat et al., 1989). In addition, the negative psychiatric effects of high intensity cocaine use may have destabilizing influences that present barriers to engaging in formal employment (Cross et al., 2001). Indeed, previous research found that frequent crack cocaine smoking was negatively associated with attaining formal employment among IDU in our study setting (Richardson et al., 2010).

Our findings further indicate that individuals who engage in disorderly income generation activities are a vulnerable population at risk for multiple negative health and social outcomes. Many of the behaviours associated with disorderly income generation activities including daily cocaine injection, daily crack cocaine smoking, binge drug use and syringe sharing, have all been independently linked with increased risk of HIV infection in this setting (DeBeck et al., 2009; Miller et al., 2006; Tyndall et al., 2003). Although many of these findings have been reported previously, they underscore the importance of identifying 
interventions to reduce engagement in disorderly income generation activities. Therefore, it is of particular importance that our primary analyses found a high demand for low-threshold employment among street-involved IDU and considerable willingness among this population to cease engaging in disorderly activities if they were provided with opportunities for casual low-threshold employment. Previously mentioned findings documenting low levels of regular employment among IDU support the need for alternative income generation interventions (Richardson et al., 2010). The potential for low-threshold employment to reduce engagement in disorderly income generation has already been demonstrated to be successful among women involved in sex work (Sherman et al., 2006). Our findings are also consistent with current literature in the drug use field that emphasizes the importance that structural factors, such as employment opportunities, play in shaping risk behaviour (Blankenship et al., 2000; Des Jarlais, 2000; Heimer et al., 2002).

The association between current enrolment in methadone treatment and willingness to give up disorderly income generation is consistent with the well-documented positive effect of methadone treatment on reducing illegal income generation (Ball \& Alan, 1991; Dole et al., 1969). This finding also suggests that substitution therapies may have an even greater beneficial role if more low-threshold opportunities were made available.

It is noteworthy that in our study participation in sex work was the strongest independent predictor of willingness to take low-threshold employment. Given the physical dangers and health risks associated with sex work, it is understandable that participants engaged in sex work were most likely to be willing to cease engaging in this behaviour if given other options to earn income (Shannon et al., 2007a; Shannon, et al., 2007b). In addition to the inherent risks associated with sex work, numerous studies have also linked prohibitive sexwork legislation with increasing the vulnerability of sex workers and undermining their ability to protect their health and physical security (Maher, 2000; Maher \& Dixon, 1999; Shannon et al., 2008; Shannon et al., 2009). Although the intention of prohibitive sex-work legislation is to deter engagement in the activity, it appears that the laws that are implemented to reduce the harms of sex work are actually increasing risks. The strong demand for low-threshold employment found in the current study among individuals engaged in sex works suggests that there are important opportunities to reduce the prevalence of this activity through means that do not criminalize sex workers and carry the unanticipated negative consequences of criminal justice interventions. It is important to note, however, that the income earned through sex work is often much greater than through other income generation opportunities. Despite the potential for sex workers to reduce their engagement in sex work if alternative low-threshold employment opportunities were made available, it is likely that the income will not be sufficient for some sex workers. In addition to supporting the development of low-threshold employment opportunities, amending laws that limit the ability of sex workers to protect their health and physical safety should be simultaneously considered and pursued.

IDU who engaged in drug dealing were also significantly more willing to cease this income generation activity if they were given alternative opportunities for low-threshold employment. Former studies of drug distribution networks suggest that many street-level drug dealers do not receive significant compensation for their work (Levitt \& Venkatesh, 2000). These works support our findings suggesting that this group may respond well to low-threshold employment opportunities. This should be of particular interest to policymakers given the high costs of drug law enforcement which attempt to deter illicit drug production and distribution with the threat of incarceration and legal penalties which, to date, have been limited in their ability to prevent engagement in drug dealing among IDU and other segments of the general population (Bewley-Taylor, Trace, \& Stevens, 2005; National Research Council, 2002; Rehm et al., 2006). 
It is clear from the high rates of engagement in disorderly income generation activities reported in our study that current direct and indirect prohibitions against practices such as drug dealing and sex work are not successfully deterring or preventing engagement in these activities. However, it is interesting to note that sex work and drug dealing, as well as recent incarceration, were all significantly associated with willingness to cease engagement in disorderly income generation activities. This may suggest that the deterrent influence of prohibitions against drug dealing and sex work could be successful in situations where IDU were given opportunities to choose other less risk income generation opportunities. Unfortunately, it currently appears that the less risky generation opportunities available to most IDU remain limited (McCoy et al., 2007; Richardson et al., 2008; Richardson et al., 2010).

A key implication of this study is that creating low-threshold employment opportunities and supporting existing initiatives that currently provide these positions has potential to reduce both street disorder and health risks currently faced by individuals who engage in disorderly income generation activities. Models of low-threshold employment for active illicit drug users already exist in our study setting and elsewhere (Hope in Shadows, 2010; LougheedGreen, 2004; Lyotier, 2010; Potluck catering, 2010; VANDU, 2010); however, our study suggests that there is a high demand for this type of work and increasing their capacity and availability has potential to reduce both individual- and community-level harms.

There are a number of limitations with this study. Firstly, VIDUS is not a random sample of IDU and therefore these findings may not generalize to other drug using populations. However, the association between crack cocaine smoking and street-based income generation suggests that our findings are likely not specific to injection as the sole mode of cocaine use and may be relevant for crack cocaine smokers that do not have a history of injecting. It should also be noted that the median age of participants in VIDUS is 45 years, which is likely higher than the general population of IDU in Vancouver. This could be expected to result in an under-estimation of risks as younger drug users tend to be more likely to engage in riskier behaviours and practices (Kral et al., 2000). Secondly, there are limitations with combining different street-based disorderly income generation activities into one category as each of these activities is unique and likely attracts different populations. It is evident from our primary analysis that there are unique characteristics among each group. Although it is crude to combine these very different activities, from a policy perspective it is meaningful to provide a picture of the net factors associated with these activities, as well as direction as to whether a potential policy intervention will likely have an overall beneficial impact despite the differences among activities. While it would have been ideal to supplement our primary analysis with additional models that considered each individual income generation activity separately, low event counts precluded these additional comparisons. An additional limitation with our variable definition is our overly broad definition of 'recycling'. Recycling can constitute a public good when it involves removing litter from public areas; however, it could alternatively constitute a public harm if it involves destructively removing materials from buildings or structures, such as copper piping. We anticipate that the demand for low-threshold employment may be higher for those involved in destructive forms of recycling given the threat of legal repercussions. Unfortunately our survey instrument did not differentiate between these different forms of recycling and thus our results are limited in this regard. We believe the distinctions between different forms of recycling are important and warrant further investigation. A third limitation in our study is that many of our measures relied on self-reported information concerning practices and behaviours that are illegal and/or stigmatized, such as drug dealing, sex work and syringe sharing and are therefore vulnerable to social desirable responding. In this present study, this could have resulted in an under-reporting of engagement in disorderly income generation activities and associated risks resulting in conservative estimates of the prevalence of these 
activities and risks. There are other limitations with our measures of street-based income generation activities. Specifically, the amount of money earned through street-based disorderly income generation activities does not account for 'in-kind' transactions or nonmonetary contributions (i.e., exchanging sex for drugs, being paid in drugs rather than money for drug dealing, or receiving food when panhandling). This could have also led to an under-reporting of engagement in street-based disorderly income generation. Lastly, our study relied on willingness responses that do not represent actual changes in income generation practices. There are potentially a host of external factors that might influence income generation practices, some of which may involve complex social networks and power relations. Therefore, the provision of low-threshold employment can not be expected to automatically translate into a reduction of street-based income generation among all participants who indicated a willingness to change their income generation practices. However, it is important to note that previous analyses evaluating the validity of reporting willingness to use a supervised injection facility on subsequent rates of use among illicit injection drug users found that willingness measures were reasonably accurate predictors of later behaviour among IDU (DeBeck, 2010).

In summary, we found that $48 \%$ of our sample of IDU recently engaged in disorderly income generation activities, and these practices were associated with high intensity stimulant drug use and various markers of risk. However, we also found that a high percentage of IDU reported being willing to cease engagement in disorderly income generation activities if they had options for causal low-threshold employment. These findings indicate that there is a high demand for low-threshold employment which may offer important opportunities to reduce drug-related street disorder and associated harms.

\section{Acknowledgments}

The authors thank the study participants for their contribution to the research, as well as current and past researchers and staff. We would specifically like to thank Deborah Graham, Tricia Collingham, Carmen Rock, Peter Vann, Caitlin Johnston, Steve Kain, and Calvin Lai for their research and administrative assistance. We also thank the anonymous peer reviewers for their constructive comments and suggestions that helped improve the manuscript. The study was supported by the US National Institutes of Health (R01DA011591) and (R01DA021525) and the Canadian Institutes of Health Research (MOP-79297, RAA-79918). Thomas Kerr is supported by the Michael Smith Foundation for Health Research and the Canadian Institutes of Health Research. Kora DeBeck is supported by a Michael Smith Foundation for Health Research Senior Graduate Trainee Award and a Canadian Institutes of Health Research Doctoral Research Award. Julio Montaner has received an Avant-Garde award (DP1DA026182) from the National Institute of Drug Abuse, US National Institutes of Health.

\section{References}

Aitken C, Moore D, Higgs P, Kelsall J, Kerger M. The impact of a police crackdown on a street drug scene: Evidence from the street. International Journal of Drug Policy. 2002; 13:189-198.

Ball, John C.; Ross, Alan. The effectiveness of methadone maintenance treatment: Patients, programs, services, and outcome. New York, NY, US: Springer-Verlag Publishing; 1991.

Ball J, Shaffer J, Nurco D. The day to-day criminality of heroin addicts in Baltimore -- A study in the continuity of offence rates. Drug and Alcohol Dependence. 1983; 12(2):119-142. [PubMed: 6653385]

Bewley-Taylor, D.; Trace, M.; Stevens, A. Beckley Foundation Drug Policy Programme. 2005. Incarceration of drug offenders: Costs and impacts.

Blankenship K, Bray S, Merson M. Structural interventions in public health. AIDS. 2000; 14:S11-S21. [PubMed: 10981470]

Blankenship K, Friedman S, Dworkin S, Mantell J. Structural interventions: Concepts, challenges and opportunities for research. Journal of Urban Health. 2006; 83(1):59-72. [PubMed: 16736355] 
Booth RE, Kwiatkowski CF, Chitwood DD. Sex related HIV risk behaviors: Differential risks among injection drug users, crack smokers, and injection drug users who smoke crack. Drug and Alcohol Dependence. 2000; 58(3):219-226. [PubMed: 10759032]

Bose R, Hwang SW. Income and spending patterns among panhandlers. Canadian Medical Association Journal. 2002; 167(5):477-479. [PubMed: 12240813]

Boyum, D.; Reuter, P. An analytic assessment of US drug policy. Washington, DC: American Enterprise Institute for Public Policy Research; 2005.

Bretteville-Jensen A, Sutton M. The income-generating behaviour of injecting drug-users in Oslo. Addiction. 1996; 91(1):63-79. [PubMed: 8822015]

Buchanan D, Tooze JA, Shaw S, Kinzly M, Heimer R, Singer M. Demographic, HIV risk behavior, and health status characteristics of crack cocaine injectors compared to other injection drug users in three New England cities. Drug and Alcohol Dependence. 2006; 81(3):221-229. [PubMed: 16171952]

Collins, D.; Blomley, N. New Perspectives on the Public-Private Divide. Law Commission of Canada; 2003. Private needs and public space: Politics, poverty, and anti-panhandling by-laws in Canadian cities; p. 40-67.

Cooper H, Wypij D, Krieger N. Police drug crackdowns and hospitalisation rates for illicit-injectionrelated infections in New York City. International Journal of Drug Policy. 2005; 16(3):150-160.

Cross JC, Johnson BD, Davis WR, Liberty HJ. Supporting the habit: Income generation activities of frequent crack users compared with frequent users of other hard drugs. Drug and Alcohol Dependence. 2001; 64(2):191-201. [PubMed: 11543989]

Dale A, Newman L. Social capital: A necessary and sufficient condition for sustainable community development? Community Development Journal. 2008; 45(1):5-21.

DeBeck K, Wood E, Zhang R, Buxton J, Montaner J, Kerr T. A dose-dependent relationship between exposure to a street-based drug scene and health-related harms among people who use injection drugs. J Urban Health. 2011 May 2. [Epub ahead of print].

DeBeck, K. Published PhD Dissertation. University of British Columbia; Vancouver, Canada: 2010. Drug-related street disorder: Evidence for public policy responses.

DeBeck K, Kerr T, Li K, Fischer B, Buxton J, Montaner J, Wood E. Emergence of crack cocaine smoking as a risk factor for HIV seroconversion among injection drug users in Vancouver, Canada. Canadian Medical Association Journal. 2009; 181(9):585-589. [PubMed: 19841052]

DeBeck K, Wood E, Montaner J, Kerr T. Canada's 2003 renewed drug strategy--an evidence-based review. HIV/AIDS Policy \& Law Review/Canadian HIV/AIDS Legal Network. 2006; 11(2-3):1, $5-12$.

DeBeck K, Shannon K, Wood E, Li K, Montaner J, Kerr T. Income generating activities of people who inject drugs. Drug and Alcohol Dependence. 2007; 91(1):50-56. [PubMed: 17561355]

Des Jarlais D. Structural interventions to reduce HIV transmission among injection drug users. AIDS. 2000; 14:S41-S46. [PubMed: 10981473]

Deschenes E, Anglin M. Narcotics addiction: Related criminal careers, social and economic costs. Journal of Drug Issues. 1991; 21(2):383.

Dole VP, Robinson JW, Orraca J, Towns E, Searcy P, Caine E. Methadone treatment of randomly selected criminal addicts. N Engl J Med. 1969; 280(25):1372-5. [PubMed: 4890477]

Edlin BR, Irwin KL, Faruque S, McCoy CB, Word C, Serrano Y, Inciardi JA, Bowser BP, Schilling RF, Holmberg SD. Intersecting epidemics--crack cocaine use and HIV infection among inner-city young adults. New England Journal of Medicine. 1994; 331(21):1422-1427. [PubMed: 7969281]

Fischier B, Medved W, Kirst M, Rehm J, Gliksman L. Illicit opiates and crime: Results of an untreated user cohort study in Toronto. Canadian Journal of Criminology-Revue. 2001; 43(2):197-217.

Galea S, Ahern J, Vlahov D. Contextual determinants of drug use risk behavior: A theoretic framework. Journal of Urban Health. 2003; 80(4):iii50-8. [PubMed: 14713671]

Grainger P. Calendar changes lives in gritty eastside. CTV. November 30.2008

Hammersley R, Forsyth A, Morrison V, Davies J. The relationship between crime and opioid use. British Journal of Addiction. 1989; 84(9):1029. [PubMed: 2790266] 
Hayashi K, Wood E, Wiebe L, Qi J, Kerr T. An external evaluation of a peer-run outreach-based syringe exchange in Vancouver, Canada. International Journal of Drug Policy. 2010; 21(5):41821. [PubMed: 20359877]

Heimer R, Bray S, Burris S, Khoshnood K, Blankenship K. Structural interventions to improve opiate maintenance. International Journal of Drug Policy. 2002; 13(2):103-111.

Hope in Shadows. Hope in shadows: Portraits of our community. Retrieved September 29, 2010, from http://www.hopeinshadows.com/welcome

Jeffcoat AR, Perez-Reyes M, Hill JM, Sadler BM, Cook CE. Cocaine disposition in humans after intravenous injection, nasal insufflation (snorting), or smoking. Drug Metabolism and Disposition. 1989; 17(2):153-159. [PubMed: 2565204]

Kerr T, Fairbairn N, Tyndall M, Marsh D, Li K, Montaner J, Wood E. Predictors of non-fatal overdose among a cohort of polysubstance-using injection drug users. Drug and Alcohol Dependence. 2007; 87(1):39-45. [PubMed: 16959438]

Kerr T, Small W, Johnston C, Li K, Montaner JS, Wood E. Characteristics of injection drug users who participate in drug dealing: Implications for drug policy. Journal of Psychoactive Drugs. 2008; 40(2):147-152. [PubMed: 18720663]

Kral AH, Lorvick J, Edlin BR. Sex-and drug-related risk among populations of younger and older injection drug users in adjacent neighborhoods in San Francisco. JAIDS. 2000; 24(2):162. [PubMed: 10935692]

Levitt SD, Venkatesh SA. An economic analysis of a drug-selling gang's finances. Quarterly Journal of Economics. 2000; 115(3):755-789.

Lloyd-Smith E, Rachlis B, Tobin D, Stone D, Li K, Small W, Wood E, Kerr T. Assisted injection in outdoor venues: An observational study of risks and implications for service delivery and harm reduction programming. Harm Reduction Journal. 2010; 7:6-10. [PubMed: 20302638]

Lougheed-Green L. The potluck café: Navigating the "twilight zone" of social enterprise. Making Waves. 2004; 15(3):5-9.

Lyotier, K. United we can: A street charity that means business. Retrieved September 29, 2010, from http://www.unitedwecan.ca/

Maher, L. Sexed work: Gender, race, and resistance in a Brooklyn drug market. USA: Oxford University Press; 2000.

Maher L, Dixon D. Policing and public health: Law enforcement and harm minimization in a streetlevel drug market. British Journal of Criminology. 1999; 39(4):488-512.

McCoy CB, Comerford M, Metsch LR. Employment among chronic drug users at baseline and 6month follow-up. Substance use \& Misuse. 2007; 42(7):1055-1067. [PubMed: 17668325]

Miller CL, Kerr T, Frankish JC, Spittal PM, Li K, Schechter MT, Wood E. Binge drug use independently predicts HIV seroconversion among injection drug users: Implications for public health strategies. Substance use \& Misuse. 2006; 41(2):199-210. [PubMed: 16393742]

Moore S, Pell S. Autonomous archives. International Journal of Heritage Studies. 2010; 16(4):255268.

National Research Council. Executive summary of the national research councils report informing Americas' policy on illegal drugs: What we don't know keeps hurting us. Addiction. 2002; 97(6): 647-652. [PubMed: 12084127]

Nurco D, Cisin I, Ball J. Crime as a source of income for narcotic addicts. Journal of Substance Abuse Treatment. 1985; 2(2):113-115. [PubMed: 3831370]

Platt JJ. Vocational rehabilitation of drug abusers. Psychological Bulletin. 1995; 117(3):416-433. [PubMed: 7777647]

Potluck catering. Potluck training \& employment program. Retrieved September 29, 2010, from http://www.potluckcatering.org/training.html

Rehm, J.; Baliunas, D.; Brochu, S.; Fischer, B.; Gnam, W.; Patra, J.; Popova, S.; Sarnocinska-Hart, A.; Taylor, B. The costs of substance abuse in Canada 2002. The Canadian Centre on Substance Abuse; 2006.

Rhodes T. The 'risk environment': A framework for understanding and reducing drug-related harm. International J Drug Policy. 2002; 13(2):85-94. 
Rhodes T, Lilly R, Fernández C, et al. Risk factors associated with drug use: The importance of 'risk environment'. Drugs: education, prevention and policy. 2003; 10:303-329.

Rhodes T, Singer M, Bourgois P, Friedman SR, Strathdee SA. The social structural production of HIV risk among injecting drug users. Soc Sci Med. 2005; 61(5):1026-44. [PubMed: 15955404]

Rhodes T. Risk environments and drug harms: a social science for harm reduction approach. Int J Drug Policy. 2009 May; 20(3):193-201. [PubMed: 19147339]

Richardson L, Wood E, Li K, Kerr T. Factors associated with employment among a cohort of injection drug users. Drug and Alcohol Review. 2010; 29(3):293-300. [PubMed: 20565522]

Richardson L, Wood E, Zhang R, Montaner J, Tyndall M, Kerr T. Employment among users of a medically supervised safer injection facility. The American Journal of Drug and Alcohol Abuse. 2008; 34(5):519-525. [PubMed: 18821450]

Shannon K, Bright V, Allinott S, Alexson D, Gibson K, Tyndall MW. Community-based HIV prevention research among substance-using women in survival sex work: The MAKA project partnership. Harm Reduction Journal. 2007a; 4:20. [PubMed: 18067670]

Shannon K, Bright V, Gibson K, Tyndall MW. Maka Project Partnership. Sexual and drug-related vulnerabilities for HIV infection among women engaged in survival sex work in Vancouver, Canada. Canadian Journal of Public Health. 2007b; 98(6):465-469.

Shannon K, Kerr T, Allinott S, Chettiar J, Shoveller J, Tyndall MW. Social and structural violence and power relations in mitigating HIV risk of drug-using women in survival sex work. Social Science \& Medicine. 2008; 66(4):911-921. [PubMed: 18155336]

Shannon K, Strathdee SA, Shoveller J, Rusch M, Kerr T, Tyndall MW. Structural and environmental barriers to condom use negotiation with clients among female sex workers: Implications for HIVprevention strategies and policy. American Journal of Public Health. 2009; 99(4):659-65. [PubMed: 19197086]

Sherman S, German D, Cheng Y, Marks M, Bailey-Kloche M. The evaluation of the JEWEL project: An innovative economic enhancement and HIV prevention intervention study targeting drug using women involved in prostitution. AIDS Care. 2006; 18(1):1. [PubMed: 16282070]

Shtatland, ES.; Cain, E.; Barton, MB. The perils of stepwise logistic regression and how to escape them using information criteria and the output delivery system. Proceedings from the 26th Annual SAS Users Group International Conference; 2001. p. 22-25.

Silverman L, Spruill N. Urban crime and the price of heroin. Journal of Urban Economics. 1977; 4(1): 80-103.

Sumartojo E. Structural interventions in HIV prevention: Concepts, examples, and implications for research. AIDS. 2000; 14:S3-S10. [PubMed: 10981469]

Tyndall M, Currie S, Spittal P, Li K, Wood E, O'Shaughnessy M, Schechter M. Intensive injection cocaine use as the primary risk factor in the Vancouver HIV-1 epidemic. Aids. 2003; 17(6):88793. [PubMed: 12660536]

VANDU. Vancouver Area Network of Drug Users. Retrieved September 29, 2010, from http://www.vandu.org/

Wood E, Spittal P, Small W, Kerr T, Li K, Hogg R, Tyndall M, Montaner J, Schechter M. Displacement of Canada's largest public illicit drug market in response to a police crackdown. Canadian Medical Association Journal. 2004; 170(10):1551-6. [PubMed: 15136548]

Wood E, Tyndall MW, Spittal PM, Li K, Hogg RS, Montaner JS, O’Shaughnessy MV, Schechter MT. Factors associated with persistent high-risk syringe sharing in the presence of an established needle exchange programme. AIDS. 2002; 16(6):941-943. [PubMed: 11919503] 


\section{Table 1}

Participation in disorderly income generation activities among injection drug users (last six months) $(\mathrm{n}=874)$

\begin{tabular}{lccc}
\hline Income Source & $\mathbf{N}(\%)$ reporting activity & $\begin{array}{c}\text { Median hrs per week engaged in activity } \\
\text { (IQR) }\end{array}$ & N (\%) would cease to engage in activity ${ }^{* *}$ \\
\hline Recycling & $165(19)$ & $14(8-30)$ & $48(29)$ \\
Panhandling & $57(7)$ & $14(4.5-40)$ & $21(37)$ \\
Squeegeeing & $5(1)$ & $5(2-10)$ & $0(0)$ \\
Drug Dealing & $220(25)$ & $20(6-40)$ & $97(44)$ \\
Sex Work & $81(9)$ & $9(3-21)$ & $51(63)$ \\
\hline
\end{tabular}

* Refers to number of hours spent doing the activity in the average week over the last 30 days;

** Indicates participants that would cease to engage in the activity if they had other opportunities for low-threshold employment. 


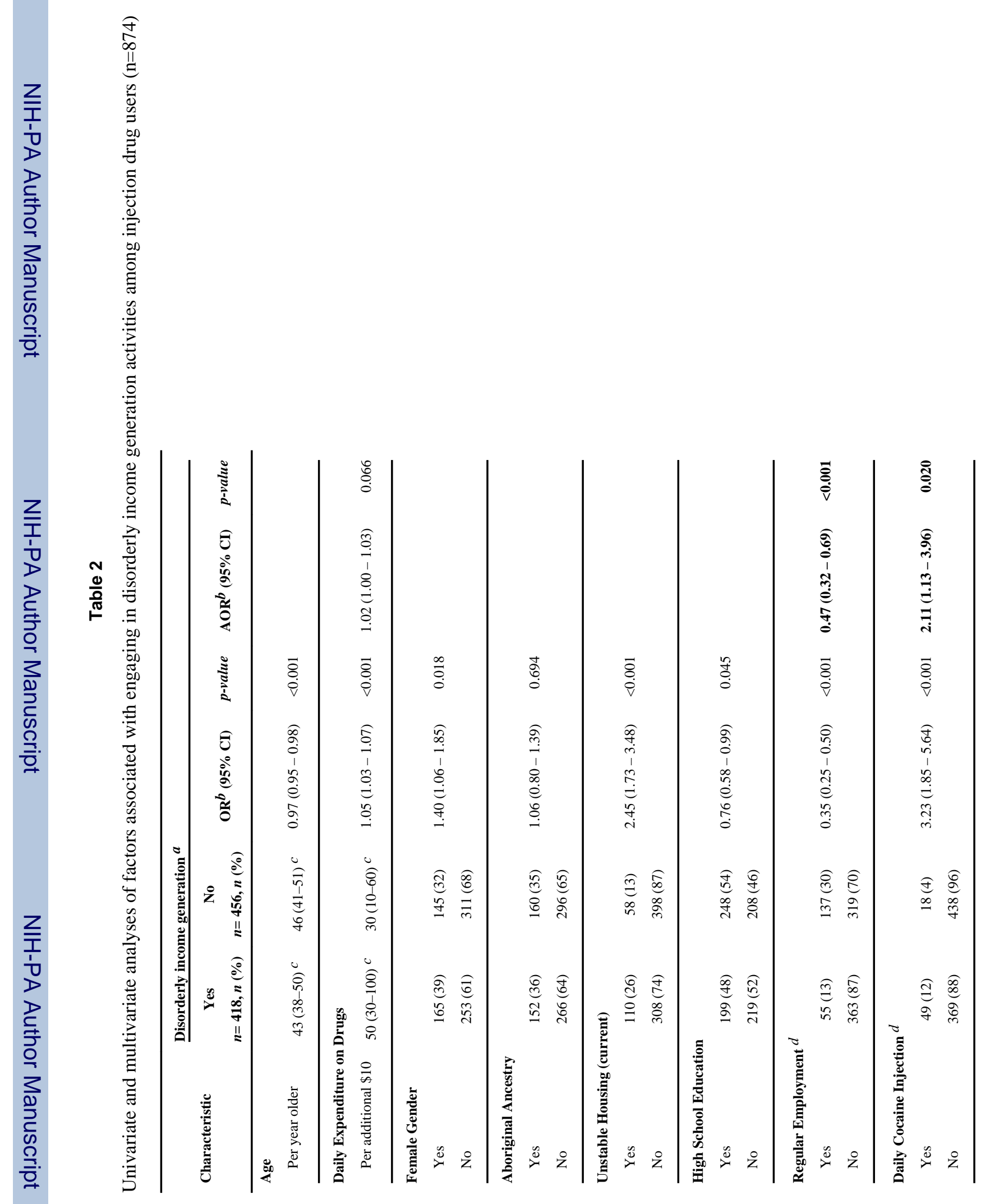




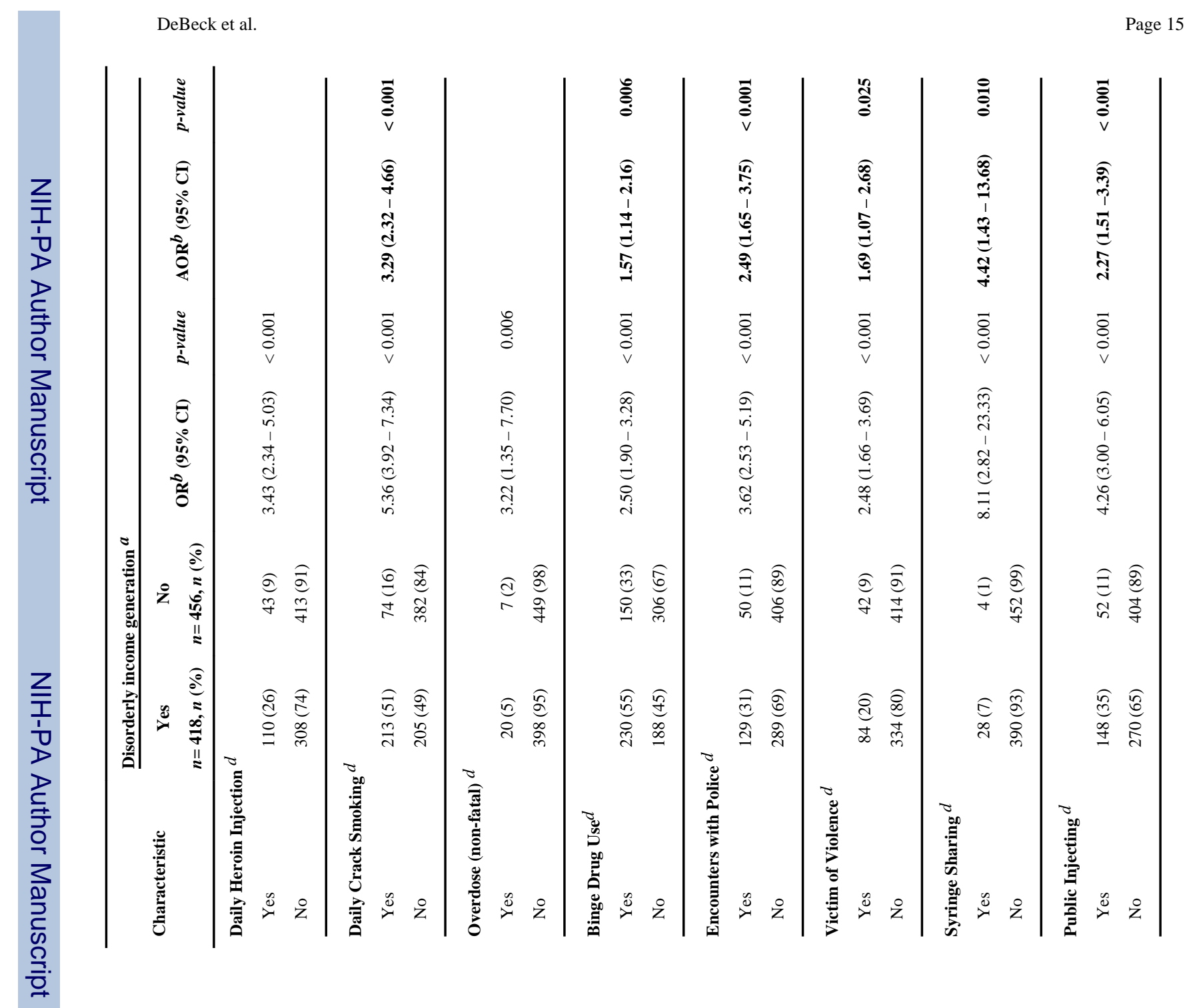

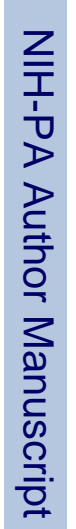

Int J Drug Policy. Author manuscript; available in PMC 2012 September 1. 


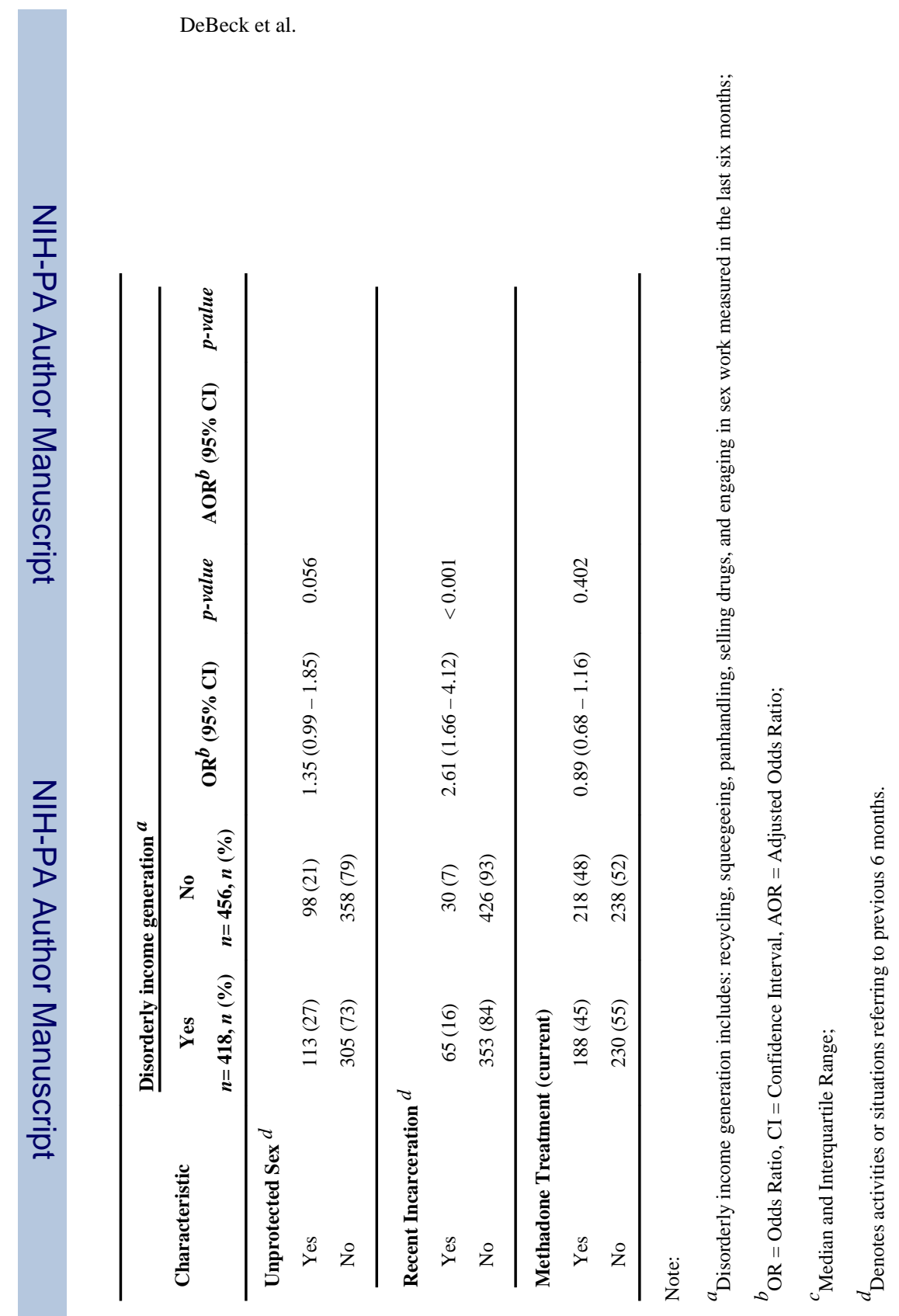

Page 16

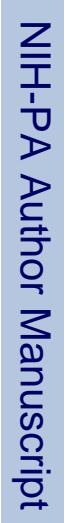

Int J Drug Policy. Author manuscript; available in PMC 2012 September 1. 


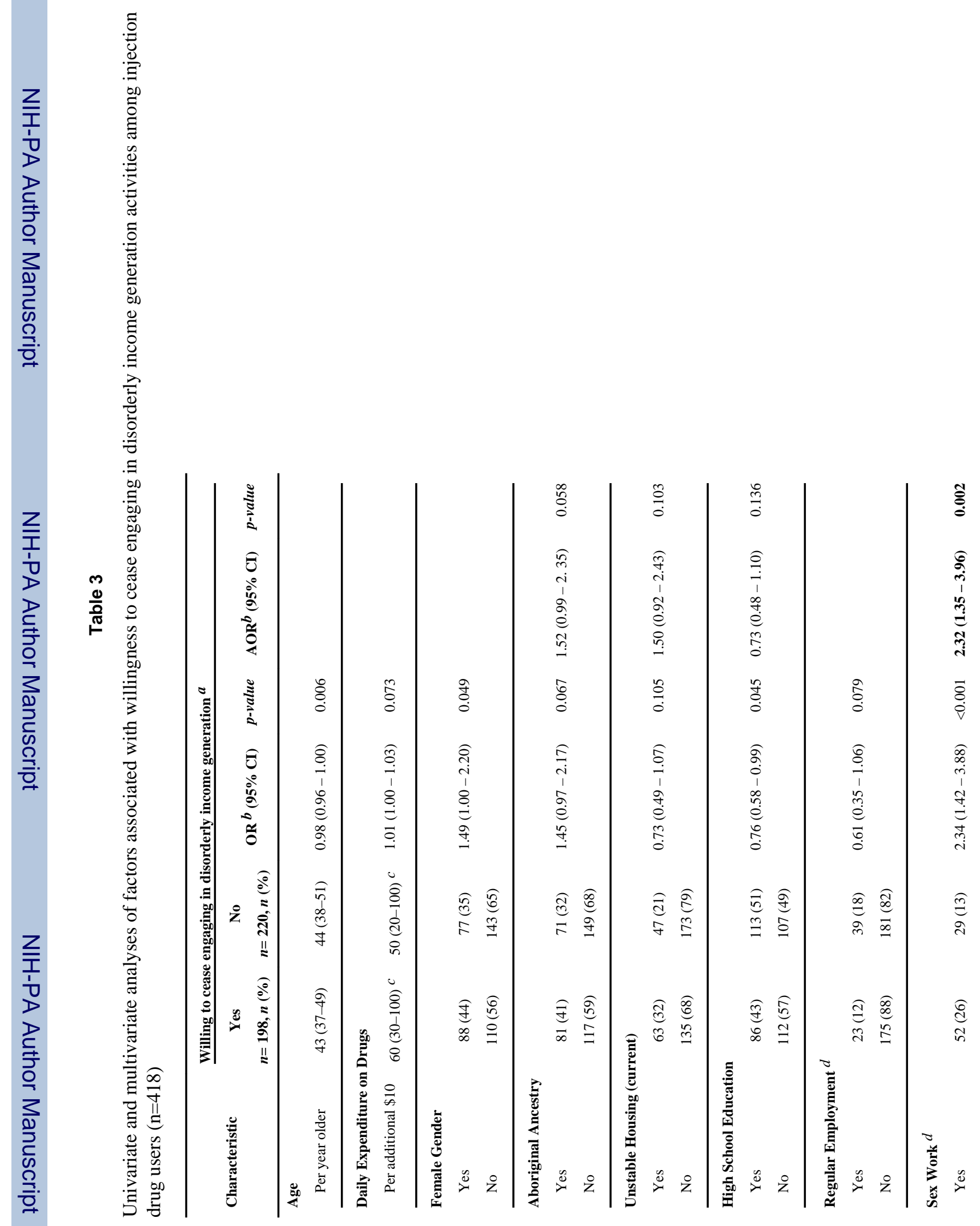




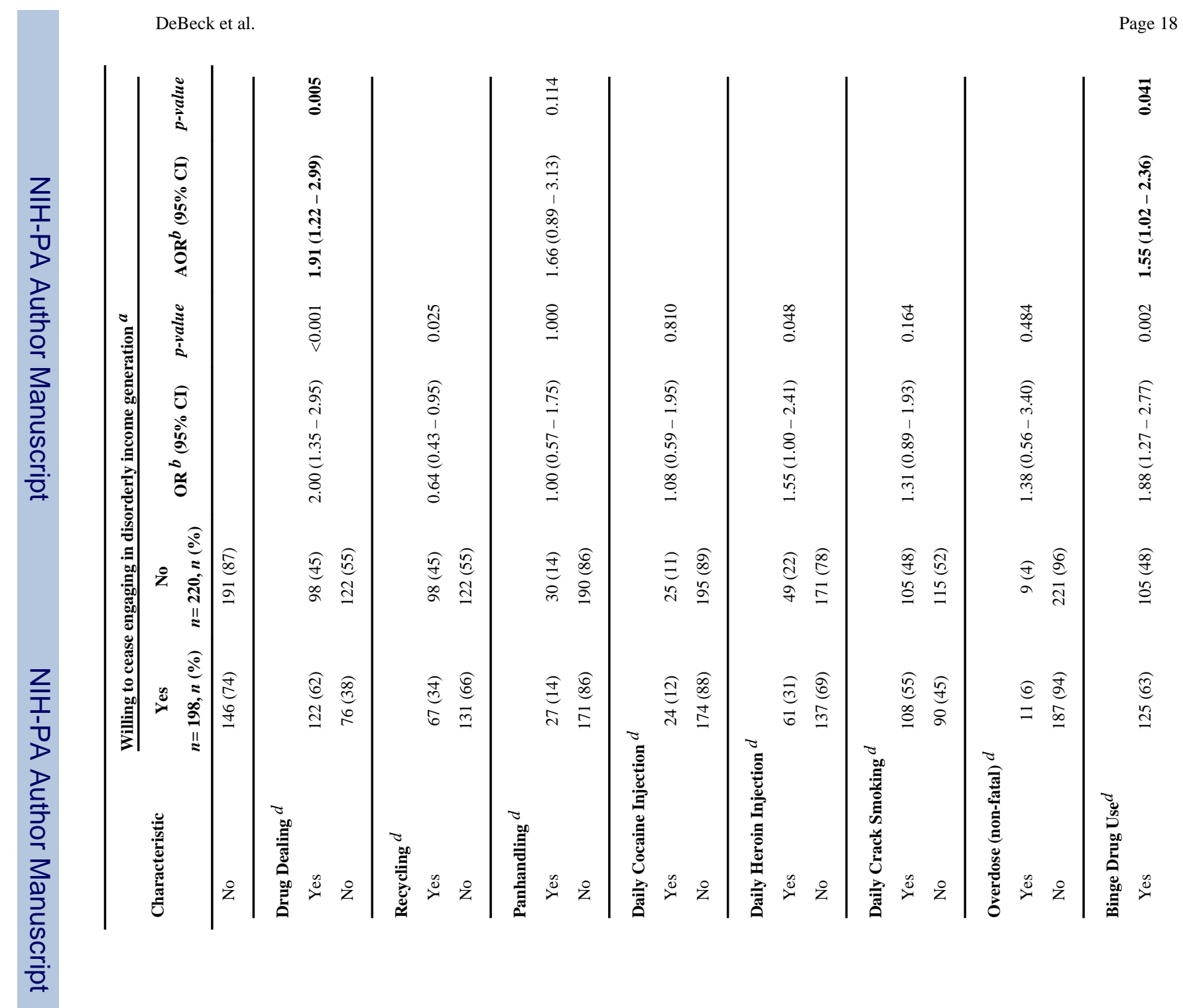

Page 18

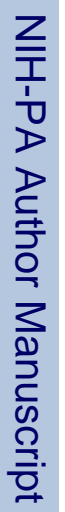

Int J Drug Policy. Author manuscript; available in PMC 2012 September 1. 
<smiles>CCC</smiles>

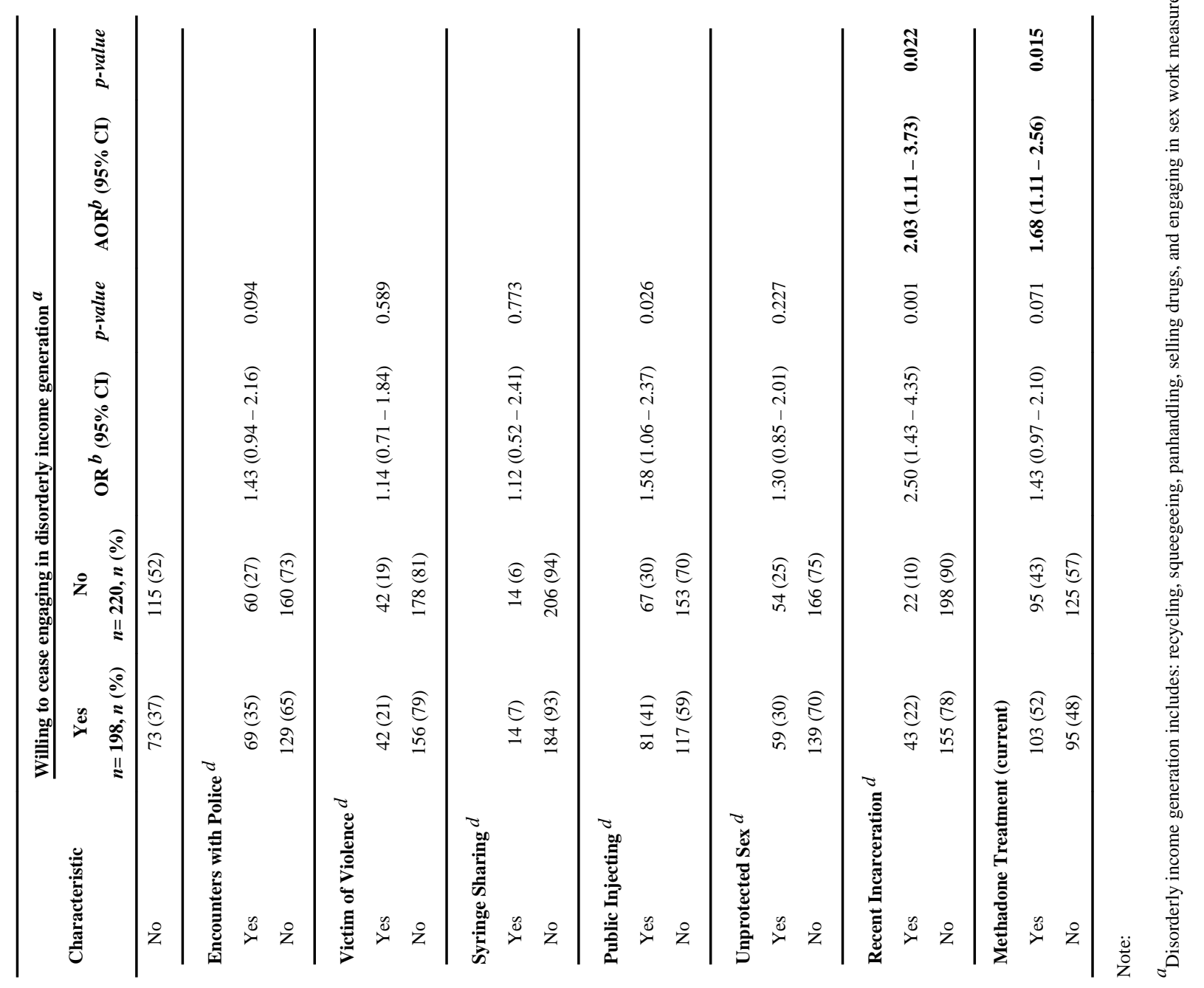


